\title{
EDitoriaL
}

\section{A promoção da saúde dos estudantes da saúde}

Muito tem sido dito e estudado sobre o adoecimento dos estudantes, futuros profissionais da saúde. Neste número, pretende-se olhar o processo saúde-doença de tal população, na perspectiva da promoção da saúde, isto é, buscar e (re)conhecer tanto fatores de risco ou desgaste quanto fatores de fortalecimento ou potencialidades, numa concepção ampliada de saúde. Além disso, é trabalhado o binômio indivíduo/coletivo, uma vez que a promoção da saúde individual está diretamente atrelada ao ambiente (no caso de ensino-aprendizagem), às políticas públicas e, sobretudo à ação comunitária desenvolvida pelos estudantes.

Partindo destas premissas e com o objetivo de enriquecer a reflexão e as práticas de Universidades Promotoras da Saúde, a Coordenação de Promoção da Saúde do NAE - Núcleo de Apoio ao Estudante da Faculdade de Medicina FMUSP da Universidade de São Paulo aceitou o convite para organizar este número temático. Estão reunidas pesquisas e experiências envolvendo estudantes e residentes, de diferentes cursos da saúde e variadas instituições de ensino do Estado de São Paulo. São exemplos entre tantas iniciativas em andamento pelo país.

Fica claro o entrelaçamento dos conceitos promoção da saúde, prevenção de doenças e qualidade de vida. A saúde mental como parte da saúde também é recorrente. Coerente com a proposta téorico-prática da promoção da saúde e com o compromisso de disseminar conhecimentos sobre educação de profissões da saúde, agradecemos o apoio da Revista para incluir duas inovações: 1) um artigo provocativo, seguindo o AMEE Fringe (espaço no Congresso da Associação Européia de Educação Médica que "provides the opportunity to see something a little different - a new and perhaps provocative or idiosyncratic approach to healthcare professions education") e 2) a sessão de relatos de experiência com formato especial de forma a dar voz a algumas das experiências desenvolvidas por estudantes.

Por fim, vale pontuar que há evidências de que programas de promoção da saúde e de prevenção de doenças para estudantes podem afetar tanto os comportamentos pessoais de saúde como também influenciar as atitudes de aconselhamento do paciente e práticas profissionais.

Boa leitura,

\author{
Ana Claudia C. G. Germani \\ Professora Doutora, Departamento de Medicina \\ Preventiva, Faculdade de Medicina FMUSP, \\ Universidade de São Paulo
}

